\title{
GEOQUÍMICA DE ROCHAS GNÁISSICAS PALEOPROTEROZÓICAS DO COMPLEXO PARAÍBA DO SUL, REGIÃO DE BARRA MANSA, RIO DE JANEIRO, BRASIL
}

\author{
C.S.Valladares ${ }^{1}$, M.C.H.Figueiredo (in memorian) ${ }^{2}$, M.Heilbron ${ }^{1}$
}

O Complexo Paraíba do Sul ocorre no Domínio Tectônico Paraíba do Sul (DTPS) ou Domínio Tectônico Superior do segmento central da Faixa Ribeira (sudeste do Brasil). Este complexo apresenta duas seqüências de características genéticas distintas: uma basal paleoproterozóica ortoderivada, composta por ortognaisses granodioríticos a graníticos, com enclaves de rochas máficas e de calciossilicáticas, denominada de Unidade Quirino; e outra metassedimentar, subdividida informalmente em Unidade Três Barras, formada por biotitagnaisses com intercalações concordante de lentes de hololeucogranitos, e Unidade São João, constituída por metapelitos com lentes de rochas calciossilicáticas e mármores sacaroidais. Os novos dados de geocronologia U-Pb permitiram separar estas duas seqüências, e restringir o termo Paraíba do Sul, às unidades metassedimentares, como Grupo Paraíba do Sul (Valladares, submetido). A zona de cisalhamento Paraiba do Sul, uma megaestrutura relacionada a D3, divide o DTPS, em dois subdomínios: Subdomínio Paraíba Norte e Subdomínio Paraíba Sul. A área estudada (sul da Folha Volta Redonda 1: 50.000) localiza-se neste último.

Foram realizadas análises geoquímicas para elementos maiores, menores e elementos traços, incluindo elementos de terras raras (ETR), em 16 rochas gnáissicas da Unidade Quirino, na área investigada. Os novos dados geoquimicos permitiram caracterizar duas séries calcioalcalinas nos ortognaisses Quirino: uma de médio a alto-K, e outra de alto-K, enriquecida em LILE.

A série calcioalcalina de médio a alto-K compreende predominantemente termos intermediários (gnaisses granodioríticos). $\mathrm{O}$ conteúdo em sílica varia de 58 a $69 \% ; \mathrm{Na}_{2} \mathrm{O}$ varia entre 3 a $4,5 \%$ e $\mathrm{K}_{2} \mathrm{O}$ fica em média em torno de $3 \%$. Outras características são: razão $\mathrm{K}_{2} \mathrm{O} / \mathrm{Na}_{2} \mathrm{O}<1 ; \mathrm{Al}_{2} \mathrm{O}_{3}>15 \% ; \mathrm{CaO} 3-5 \% ; \mathrm{Fe}_{2} \mathrm{O}_{3}$ 5-9\%; e $\mathrm{Cr} 19$ a 153 ppm. Em termos dos elementos traços incompativeis esta série apresenta: $\mathrm{Rb}$ (110-195 ppm), $\mathrm{Ba}$ (352-816 ppm), $\mathrm{Zr}$ (139-195 ppm) e Th (8-19 ppm). O padrão de distribuição de ETR normalizado para condrito, é moderadamente fracionado $\left(\mathrm{La}_{\mathrm{N}} / \mathrm{Yb}_{\mathrm{N}} 22-10\right)$, com padrão subhorizontal de TRP $\left(\mathrm{Yb}_{\mathrm{N}}\right.$ 9-7), e anomalia negativa de $\mathrm{Eu}\left(\mathrm{Eu} / \mathrm{Eu}^{*}=0,52-0,68\right)$. 0 conteúdo total de $\mathrm{ETR}$, o conteúdo de $\mathrm{Eu}$, e o fracionamento decrescem com a diferenciação, com o termo menos diferenciado apresentado LaN ca. 200 vezes o condrito.

A série calcioalcalina alto- $\mathrm{K}$ compreende predominantemente rochas ácidas (gnaisses graníticos). $\mathrm{O}$ conteúdo em $\mathrm{SiO}_{2}$ varia entre $60-72 \%, \mathrm{Na}_{2} \mathrm{O}$ entre $2-4 \%, \mathrm{~K}_{2} \mathrm{O}(3-6 \%$, em média 4,75\%), com $\mathrm{K}_{2} \mathrm{O} / \mathrm{Na}_{2} \mathrm{O}>1$, e $\mathrm{CaO} 2-4 \%$. Esta série é enriquecida em elementos incompativeis (LILE), com K (31034-47166), Rb (144-263 ppm), Ba (573-1663 ppm) e U (3-7 ppm). $\mathrm{O}$ conteúdo em Th é extremamente elevado, chegando a $72 \mathrm{ppm}$. $\mathrm{O}$ padrão de distribuição

${ }^{1}$ DGRG, Faculdade de Geologia, Universidade do Estado do Rio de Janeiro.

${ }^{2} \mathrm{DGG}$, Instituto de Geociências, Universidade de São Paulo. 
de ETR normalizado para condrito, é fortemente fracionado com, $\mathrm{La}_{N} / \mathrm{Yb}_{\mathrm{N}}=9-100$ e $\mathrm{Y}_{\mathrm{N}}=4-14$, e enriquecimento em TRL $\left(\mathrm{La}_{\mathrm{N}} / \mathrm{Sm}_{\mathrm{N}}=3-5\right)$. 0 conteúdo total de ETR é moderado nos termos intermediários $\left(\mathrm{La}_{\mathrm{N}}\right.$ ca. de 100 vezes o condrito), a elevado, nos termos ácidos $\left(\mathrm{La}_{\mathrm{N}}-400\right.$ vezes o condrito). $\mathrm{O}$ conteúdo de $\mathrm{Eu}$, decresce com a diferenciação, com anomalia negativa de $\mathrm{Eu}$ variável $\left(\mathrm{Eu} / \mathrm{Eu}^{*}=0,32-0,81\right)$. 0 conteúdo total de ETR e o fracionamento, de uma maneira geral, aumentam com a diferenciação.

Estas duas séries podem ter sido geradas durante o mesmo evento colisional no Transamazônico. Os dados geoquímicos sugerem que a série de médio a alto-K representa o magmatismo calcioalcalino pré-colisional e a série calcioalcalina alto-K representa o magmatismo pós-colisional, gerada sob crosta espessada.

A Unidade Quirino, ocorre como extensos corpos de gnaisses homogêneos em fácies anfibolito alto, localmente migmatíticos, com hornblenda e/ou biotita, perfazendo ca. de $50 \%$ da área mapeada. Regionalmente integram por volta de $70 \%$ em superficie do Dominio Tectônico Paraíba do Sul no segmento central da Faixa Ribeira. A Unidade Quirino foi gerada a $2185 \pm 8 \mathrm{Ma}$ e $2169 \pm 3 \mathrm{Ma}$ (dados U-Pb em zircão; Machado et al., 1996), e está temporalmente relacionada à evolução do ciclo Transamazônico. Estas idades, definidas por interceptos superiores de análises de zircões, foram obtidas nos ortognaisses Quirino a sul e a norte da Zona de Cisalhamento do Rio Paraíba do Sul, respectivamente. As idades minimas de 2846 Ma e 2981 $\mathrm{Ma}$, obtidas em zircões dos gnaisses granodioriticos da Unidade Quirino, aflorantes ao norte da Zona de Cisalhamento Paraiba do Sul, revelam a pré-existência de crosta arqueana como fonte de $\mathrm{Pb}$ para parte dos gnaisses investigados.

As linhas de discórdia definidas pelas análises de zircão dos ortognaisses da Unidade Quirino geraram interceptos inferiores de $605 \pm 3 \mathrm{Ma}$ e $571 \pm 3 \mathrm{Ma}$. Titanitas escuras dos ortognaisses graníticos forneceram idade máxima de crescimento deste mineral a $577 \pm 1 \mathrm{Ma}$. Titanitas dos leucossomas de rocha máfica relacionada à esta unidade revelam fusão parcial a $584 \pm 2$ Ma. Estes dados indicam remobilização das rochas da Unidade Quirino, durante a orogênese Brasiliana.

\section{Referências Bibliográficas}

MACHADO, N.; VALLADARES, C.S.; HEILBRON, M.; VALERIANO, C.M. (no prelo) U$\mathrm{Pb}$ geochronology of the central Ribeira Belt (Brazil) and implications for the evolution of the Brazilian Orogeny. Precambrian Research, v.78.

VALLADARES, C.S. (1996) Evolução geológica do Complexo Paraíba do Sul, no segmento central da Faixa Ribeira, com base em estudos de geoquímica e geocronologia U-Pb. São Paulo, 147p. (Tese - Doutorado) - Instituto de Geociências, Universidade de São Paulo. 